\title{
FAKTOR-FAKTOR DOMINAN YANG MEMPENGARUHI KEPATUHANI ORANGTUA YANG MEMPUNYAI ANAK DENGAN LEUKEMIA DALAM MENJALANI TERAPI KEMOTERAPI DI RB4 RSUP H.A.MALIK MEDAN TAHUN 2014
}

\author{
Tiurlan Mariasima Doloksaribu, Risma Dumiri Manurung \\ Jurusan Keperawatan Poltekkes Kemenkes Medan
}

\begin{abstract}
Abstrak
Leukemia adalah jenis kanker darah, dimana sel darah putih diproduksi melebihi yang seharusnya ada. Leukemia adalah keganasan yang mewakili hampir sepertiga dari semua kanker pada anak, ditandai dengan pucat, kelelahan, memar dan ptekie, nyeri tulang, demam, hepatosplenomegali, limfadenopati, anemia, neutropenia, dan trombositopenia. Terapi paling efektif untuk penyembuhannya adalah kemoterapi. Tujuan penelitian untuk mengetahui faktor-faktor dominan yang mempengaruhi orangtua sebagai support sistem utama bagi anak dalam kepatuhan menjalani kemoterapi. Jenis penelitian deskriptif dengan desain cross sectional. Instrumen penelitian menggunakan kuesioner dengan analisis univariat dan bivariat dengan uji chi-square. Jumlah sampel 18 responden. Hasil penelitian dengan analisis univariat menunjukkan, tingkat sosial ekonomi responden mayoritas adalah keluarga sejahtera III sebanyak 8 responden $(44,4 \%)$, tingkat pengetahuan baik sebanyak 10 responden $(55,6 \%)$ dan berdasarkan kelompok umur, sebanyak 7 responden $(38,88 \%)$ kelompok umur 40-49 tahun, 6 responden (33.3\%) kelompok umur 30-39 tahun. Analisis bivariat, menurut tingkat sosial ekonomi dari keluarga sejahtera III sebanyak 7 responden $(38,8 \%)$ patuh, sedangkan yang tidak patuh pada keluarga sejahtera I dan II masing-masing sebanyak 2 responden $(11,11 \%)$. Responden yang berpengetahuan baik dan patuh mengikuti kemoterapi sebanyak 8 orang $(44,4 \%)$ sedangkan yang berpengetahuan kurang dan tidak patuh sebanyak 2 responden $(11,1 \%)$. Berdasarkan kelompok umur 30-39 tahun, dari 6 responden sebanyak 5 responden $(83,3 \%)$ patuh, kelompok usia 50-59 tahun dari 2 responden sebanyak 1 responden (50\%) tidak patuh. Berdasarkan hasil penelitian, pengetahuan merupakan faktor paling dominan yang mempengaruhi kepatuhan orangtua dalam menjalankan kemoterapi bagi anaknya, sehingga disarankan bagi petugas kesehatan untuk memberikan seluas-luasnya informasi tentang penyakit leukemia dan pengobatan yang efektif (kemoterapi) kepada orangtua dengan anak penderita leukemia dalam menjalankan kemoterapi.
\end{abstract}

Kata Kunci : Leukemia, Kepatuhan orangtua, Kemoterapi

\section{PENDAHULUAN}

Organisasi Kesehatan Dunia memperkirakan, penderita kanker bertambah 6,25 juta per tahun di seluruh dunia. Di Indonesia, diprediksi tiap tahun ada seratus penderita baru dari 100.000 penduduk, 2 persen diantaranya atau 4.100 kasus merupakan kanker anak. Angka ini terus meningkat akibat kurangnya pemahaman orang tua mengenai penyakit kanker dan bahayanya (Cecile \& Linda, 2009).

Kanker pada anak menurut Birch dan Marsden yang diakui oleh World Health Organization (WHO), terdapat 12 jenis kanker pada anak (Gupta, et al. dalam Pinkerton, Shankar, Matthay, 2007). Leukemia Limfoblastik Akut (LLA) paling banyak dari semua kanker anak (Duchoslav, 2010). Sesuai data American Cancer Society (2006, dalam Campbell, et al. 2008b) LLA adalah jenis kanker yang paling umum menyerang anak-anak, terhitung hampir sepertiga dari semua diagnosis kanker pada anak di Amerika. Leukemia merupakan jenis kanker yang paling banyak dijumpai pada anak-anak atau berkisar 25-30 persen dari total jumlah kasus yang ada (Cecile \& Linda, 2009). Dari semua jenis leukemia, Limfoblastic Leukemia Akut (LLA) adalah kanker yang paling umum pada anak-anak, yang mewakili 23\% dari diagnosa kanker diantara anak-anak muda sejak 15 tahun terakhir ini. Penyakit ini terjadi pada sekitar $80 \%$ dari semua kasus leukemia pada anak-anak. Puncak insiden terjadi di kelompok usia antara 2-5 tahun dan mempengaruhi anak laki-laki lebih dari perempuan. LLA adalah keganasan yang paling umum didiagnosis pada anak-anak, yang mewakili hampir sepertiga dari semua kanker pediatrik. Tingkat kejadian tahunan untuk LLA mencapai 30,9 kasus per 100 juta penduduk (Meyer et al, 2006.)

Menurut Luxner (2005) Leukemia adalah penyakit hemopoietik ganas yang ditandai dengan proliferasi limfosit tidak terbatas, terjadi perubahan yang sangat cepat dimana sel-sel tersebut menggantikan elemen sumsum darah normal. Sebanyak 50\% anak dengan LLA mengalami pucat, kelelahan, memar, dan ptekie, $25 \%$ 
mengalami nyeri tulang, 60\% demam dan hepatosplenomegali serta $50 \%$ mengalami limfadenopati, terkadang ditemukan adanya massa pada mediastinum. Luxner (2005) menyebutkan lebih jelas bahwa anak dengan LLA mengalami anemia, neutropenia, dan trombositopenia. Anemia mengakibatkan kelelahan, kelemahan, pucat, dan lesu. Neutropenia menyebabkan demam dan infeksi sedangkan trombositopenia mengakibatkan kulit memar atau purpura, ptekie, epistaksis, melena, dan perdarahan gusi. Infiltrasi leukemia juga menyebabkan hepatosplenomegali, limfadenopati, nyeri tulang dan sendi, anoreksia, nyeri perut, dan penurunan berat badan. Sondheimer (2008). Leukemia adalah suatu jenis kanker darah, dimana sel darah putih diproduksi melebihi yang seharusnya ada.

Pengobatan anak dengan LLA mencakup tiga komponen yaitu kemoterapi, radiasi, dan kemoterapi dengan transplantasi sel induk (Duchoslav, 2010). Pengobatan ini menggunakan bahan-bahan kimia untuk membunuh sel kanker. Prinsip kemoterapi adalah mencegah sel-sel kanker untuk membelah diri, menyerang dan menyebar. Kemoterapi mempengaruhi perbanyakan dan pertumbuhan sel tumor, khususnya sel dengan tingkat perbanyakan yang sangat cepat (Duchoslav, 2010).

Kemoterapi berperan paling efektif pada pengobatan awal atau pengobatan primer bila dibandingkan dengan metode lain seperti bedah atau terapi radiasi. Dengan modalitas pengobatan yang ada sekarang, bentuk terapi ini menawarkan kesempatan terbesar untuk menyembuhkan pasien dengan kanker. Namun keputusan medis bagi seorang pasien leukemia untuk melakukan kemoterapi merupakan suatu keputusan yang akan mengeluarkan biaya hidup yang besar serta memerlukan kepatuhan yang cukup tinggi untuk menjalani terapi tersebut (Cecile \& Linda, 2009).

Keluarga memainkan peranan yang sangat penting dalam pengelolaan medis anak-anak (Bart \& Smeth 1994). Kepatuhan orangtua pasien anak dengan leukemia dalam menjalani tindakan kemoterapi sangat diperlukan, mengingat anak penderita leukemia harus menjalani tindakan kemoterapi sampai batas yang ditentukan oleh professional kesehatan. Ashley (2010), menyatakan setiap anak yang menderita leukemia menjalani durasi pengobatan kemoterapi yang berbedabeda. Ada yang mengikutinya secara harian, mingguan maupun bulanan, hal ini dikarenakan berbedanya kekuatan tubuh seorang anak penderita leukemia dalam mengikuti kemoterapi. Pada kenyataannya belum semua anak penderita leukemia menunjukan kepatuhan dalam menjalani kemoterapi tersebut.

Savage et al (2008) mengemukakan bahwa secara umum ketidaktaatan meningkatkan resiko berkembangnya masalah kesehatan atau memperpanjang dan memperburuk kesakitan yang diderita. Hurlock (1980) menyebutkan ketidaktaatan ini sebagai masalah medis yang berat dan mentaati rekomendasi pengobatan yang dianjurkan dokter merupakan masalah yang sangat penting. Tingkat ketidaktaatan ini terbukti cukup tinggi dalam seluruh populasi medis yang kronis.
Dunbar dan Stunkard (dalam Neil, 2009) mengemukakan bahwa ketidakpatuhan pasien telah menjadi masalah serius yang dihadapi tenaga kesehatan profesional, untuk itu perlu diketahui tentang kepatuhan serta faktor-faktor yang mempengaruhi ketidakpatuhan pasien. Hal ini terlihat dari data yang diperoleh dari RSUP. H. Adam Malik Medan pada tahun 2012 yaitu dari 45 penderita leukemia, yang menjalani kemoterapi sebanyak 38 orang dan hanya 22 orang diantaranya yang patuh dalam menjalani kemoterapi sedangkan pada tahun 2013 dari 84 orang anak penderita leukemia, yang menjalani kemoterapi sebanyak 63 orang dan hanya 48 orang $(76,1 \%)$ yang patuh menjalani kemoterapi. Melihat fenomena diatas penulis tertarik untuk meneliti faktor dominan apa sajakah yang mempengaruhi kepatuhan orangtua yang mempunyai anak yang menderita leukemia dalam menjalani tindakan kemoterapi di ruang Rindu B4 RSUP.H.Adam Malik Medan.

\section{METODE PENELITIAN}

Desain penelitian adalah desain penelitian cross sectional, yaitu suatu metode yang merupakan rancangan penelitian dengan melakukan pengukuran atau pengamatan pada saat bersamaan (sekali waktu) dengan jenis penelitian deskriptif yang bertujuan untuk mengetahui faktor-faktor dominan yang mempengaruhi kepatuhan orangtua yang mempunyai anak dengan leukemia dalam menjalani kemoterapi di ruang rindu B4 RSUP.H.Adam Malik Medan 2014.

Populasi penelitian adalah semua orangtua yang mempunyai anak leukemia yang menjalani kemoterapi pada bulan Juli-Agustus 2014 di ruang Rindu B4 RSUP.H.Adam Malik Medan. Pengambilan sampel dengan teknik accidental sampling yaitu semua orangtua yang secara kebetulan bertemu selama penelitian, hingga terpenuhi jumlah sampel yang diinginkan yaitu berjumlah 18 orang. Jenis pengumpulan adalah jenis data primer yaitu data yang langsung diperoleh secara langsung oleh peneliti terhadap sasaran, menjelaskan tujuan penelitian, memberikan surat persetujuan menjadi responden, dan memberi kuesioner yang berbentuk multiple choise (kuesioner tertutup), setelah diisi dikumpul kembali untuk diperiksa kelengkapannya.

\section{HASIL PENELITIAN}

Responden sebanyak 18 orangtua dari anak dengan leukemia yang mengikuti kemoterapi di Ruang Rindu B4. H. Adam Malik Medan.

Tabel 1. Distribusi frekuensi berdasarkan tingkat sosial ekonomi orangtua anak pasien leukemia yang menjalani kemoterapi di ruang RB4 RSUP. H. Adam Malik Medan tahun 2014.

\begin{tabular}{lcc}
\hline Sosial Ekonomi & F & $\%$ \\
\hline Keluarga Sejahtera I & 3 & 16,7 \\
Keluarga Sejahtera II & 6 & 33,3 \\
Keluarga Sejahtera III & 8 & 44,4 \\
Keluarga Sejahtera IV & 1 & 5,6 \\
\hline Jumlah & 18 & 100 \\
\hline
\end{tabular}


Tingkat sosial ekonomi mayoritas adalah keluarga sejahtera III yaitu sebanyak 8 orang $(44,4 \%)$.

Tabel 2. Distribusi frekuensi tingkat sosial ekonomi orangtua pasien anak leukemia yang menjalani terapi kemoterapi di ruang RB4 RSUP. H. Adam Malik Medan tahun 2014.

\begin{tabular}{lcccccc}
\hline \multicolumn{1}{c}{ Sosial } & \multicolumn{2}{c}{ Patuh } & \multicolumn{2}{c}{ Tidak Patuh } & \multicolumn{2}{c}{ Jlh } \\
\multicolumn{1}{c}{ Ekonomi } & F & $\%$ & F & $\%$ & F & $\%$ \\
\hline $\begin{array}{l}\text { Keluarga } \\
\text { Sejahtera I }\end{array}$ & 1 & 5,56 & 2 & 11,1 & 3 & 16,6 \\
$\begin{array}{l}\text { Keluarga } \\
\begin{array}{l}\text { Sejahtera II } \\
\text { Keluarga }\end{array}\end{array}$ & 4 & 22,2 & 2 & 11,1 & 6 & 33,3 \\
$\begin{array}{l}\text { Sejahtera III } \\
\begin{array}{l}\text { Keluarga } \\
\text { Sejahtera IV }\end{array}\end{array}$ & 7 & 38,8 & 1 & 5,56 & 8 & 44,4 \\
\hline Jumlah & 1 & 5,56 & - & - & 1 & 5,56 \\
\hline
\end{tabular}

Tingkat sosial ekonomi responden pada keluarga sejahtera III sebanyak 7 orang $(38,88 \%)$ patuh, sedangkan responden yang tidak patuh pada keluarga sejahtera I dan II masing-masing sebanyak 2 orang $(11,11 \%)$.

Tabel 3. Distribusi frekuensi berdasarkan tingkat pengetahuan orangtua pasien anak leukemia yang menjalani terapi kemoterapi di RB4 RSUP. H. Adam Malik Medan Tahun 2014.

\begin{tabular}{lcc}
\hline \multicolumn{1}{c}{ Pengetahuan } & F & $\%$ \\
\hline Baik & 10 & 55,6 \\
Cukup & 6 & 33,3 \\
Kurang baik & 2 & 11,1 \\
Tidak baik & - & - \\
\hline Jumlah & 18 & 100 \\
\hline
\end{tabular}

Tingkat pengetahuan orangtua pasien anak leukemia mayoritas adalah baik yaitu sebanyak 10 orang $(55,6 \%)$.

Tabel 4. Distribusi tingkat pengetahuan orangtua pasien anak leukemia yang menjalani terapi kemoterapi berdasarkan kepatuhan di RB4 RSUP. H. Adam Malik Medan tahun 2014.

\begin{tabular}{lcccccc}
\hline Penge- & \multicolumn{2}{c}{ Patuh } & \multicolumn{2}{c}{ Tidak Patuh } & \multicolumn{2}{c}{ Jlh } \\
tahuan & F & $\%$ & F & $\%$ & F & $\%$ \\
\hline Baik & 8 & 44,4 & 2 & 11,1 & 10 & 55,5 \\
Cukup & 5 & 27,7 & 1 & 5,5 & 6 & 33,3 \\
$\begin{array}{l}\text { Kurang } \\
\text { baik }\end{array}$ & - & - & 2 & 11,1 & 2 & 11,1 \\
\hline Jumlah & 13 & 72,2 & 5 & 27,7 & 18 & 100 \\
\hline
\end{tabular}

Responden yang berpengetahuan baik dan patuh mengikuti kemoterapi sebanyak 8 orang $(44,4 \%)$ sedangkan responden yang berpengetahuan kurang dan tidak patuh sebanyak 2 orang $(11,1 \%)$.
Tabel 5. Distribusi frekuensi berdasarkan umur orangtua pasien anak leukemia yang menjalani terapi kemoterapi di RB4 RSUP. H. Adam Malik Medan tahun 2014.

\begin{tabular}{lcc}
\hline \multicolumn{1}{c}{ Umur } & F & $\%$ \\
\hline $20-29$ & 3 & 16,7 \\
$30-39$ & 6 & 33,3 \\
$40-49$ & 7 & 38,9 \\
$50-59$ & 2 & 11,1 \\
\hline Jumlah & 18 & 100 \\
\hline
\end{tabular}

Berdasarkan kelompok umur, sebanyak 7 orang (38,88\%) orangtua pada kelompok umur 40-49 tahun, sebanyak 6 orang $33.3 \%$ ) orangtua pada kelompok umur 30-39 tahun.

Tabel 6. Distribusi frekuensi umur orangtua pasien anak leukemia yang menjalani terapi kemoterapi berdasarkan kepatuhan di RB4 RSUP. H. Adam Malik Medan tahun 2010.

\begin{tabular}{lcccccc}
\hline Umur & \multicolumn{2}{c}{ Patuh } & \multicolumn{2}{c}{ Tidak patuh } & \multicolumn{2}{c}{ Jumlah } \\
\cline { 2 - 7 } & F & $\%$ & F & $\%$ & F & $\%$ \\
$20-29$ & 3 & 16,6 & - & - & 3 & 16,6 \\
$30-39$ & 5 & 27,7 & 1 & 5,5 & 6 & 33,3 \\
$40-49$ & 4 & 22,2 & 3 & 16,7 & 7 & 38,9 \\
$50-59$ & 1 & 5,6 & 1 & 5,5 & 2 & 11,1 \\
\hline Jumlah & 13 & 72,2 & 5 & 27,8 & 18 & 100 \\
\hline
\end{tabular}

Berdasarkan kelompok umur, sebanyak 5 responden $(27,78 \%)$ pada kelompok umur 30-30 tahun patuh dan kelompok umur 40-49 sebanyak 3 responden $(16,7 \%)$ tidak patuh.

\section{PEMBAHASAN}

Keberhasilan program pengobatan pasien leukemia dalam manjalani kemoterapi sangatlah dipengaruhi oleh kepatuhan keluarga pasien itu sendiri dalam menjalani terapi kemoterapi yang telah ditentukan oleh profesional kesehatan. Faktor-faktor yang mempengaruhi kepatuhan orangtua pasien anak leukemia yang menjalani kemoterapi di RB4 RSUP. H. Adam Malik Medan tahun 2010.

\section{Sosial Ekonomi}

Tingkat sosial ekonomi responden pada keluarga sejahtera III sebanyak 7 orang $(38,88 \%)$ patuh, sedangkan responden yang tidak patuh pada keluarga sejahtera I dan II masing-masing sebanyak 2 orang $(11,11 \%)$.

Tingkat sosial ekonomi seseorang mempengaruhi kepatuhan seseorang dalam mengikuti program pengobatan yang dikarenakan oleh adanya perbedaan tingkat kesejahteraan seseorang. Sachwartz dan Griffin dalam buku Psikologi Kesehatan karangan Bart \& Smeth yang mengatakan bahwa perilaku ketaatan pasien berhubungan dengan tingkat finansial ataupun tingkat kesejahteraan pasien dalam memenuhi kebutuhan hidup dengan baik kebutuhan hidup sehari-hari, kebutuhan perkembangan maupun kebutuhan akan pemenuhan kesehatan. Adapun responden yang memiliki tingkat kesejahteraan yang rendah memungkinkan responden 
untuk patuh dalam terapi maupun pengobatan menjadi berkurang.

\section{Pengetahuan}

Responden yang berpengetahuan baik dan patuh mengikuti kemoterapi sebanyak 8 orang $(44,4 \%)$ sedangkan responden yang berpengetahuan kurang dan tidak patuh sebanyak 2 orang $(11,1 \%)$. Pengetahuan seseorang mempengaruhi kepatuhannya dalam program pengobatan. Semakin tinggi pengetahuan seseorang maka semakin tinggi kemampuan cita, rasa, dan karsa yang dimiliki seseorang tersebut sehingga semakin baik pula perilakunya. Namun masih ditemukan responden dengan tingkat pengetahuan baik mempunyai kepatuhan yang kurang yaitu 2 orang $(11,11 \%)$, hal ini dapat dihubungkan dengan faktor lain yang mempengaruhi seperti kesibukan bekerja dan kesadaran untuk mengontrol anak yang kurang yang menyebabkan kepatuhan akan pengobatan menjadi berkurang.

\section{Umur}

Berdasarkan kelompok umur 30-39 tahun, dari 6 responden sebanyak 5 responden $(83,3 \%)$ patuh. Hal ini dikarenakan pada usia ini merupakan masa berkembangnya keseriusan bekerja serta usaha-usaha mempertahankan keberhasilan sehingga dalam hal ini memotivasi orangtua anak untuk patuh terhadap kemoterapi agar kondisi kesehatan anaknya tetap terjaga sehingga tidak mengganggu segala aktifitasnya. Responden pada kelompok usia 50-59 tahun dari 2 responden sebanyak 1 responden $(50 \%)$ tidak patuh karena pada usia ini merupakan masa dimana berkurangnya kemampuan dan kekuatan terhadap stres, berkurangnya minat dan masa penerimaan atas perubahan-perubahan yang terjadi baik dari perubahan fisik maupun psikis sehingga mengurangi motivasi untuk tetap patuh dalam menjalani terapi kemoterapi.

\section{SIMPULAN}

Dari hasil penelitian terhadap faktor-faktor yang mempengaruhi kepatuhan orangtua yang mempunyai anak dengan leukemia dalam menjalani terapi kemoterapi di RB4 RSUP H. Adam Malik Medan tahun 2014 dengan jumlah responden 18 orang didapatkan bahwa status ekonomi keluarga dan tingkat pengetahuan yang baik sangat mempengaruhi kepatuhan orangtua untuk membawa anaknya menjalankan terapi kemoterapi sesuai dengan regimen pengobatan. Umur orangtua juga mempengaruhi kepatuhannya membawa anaknya mengikuti kemoterapi. Orangtua pada kelompok umur 3039 , sebanyak $5(83,3 \%)$ dari 6 orang patuh membawa anaknya menjalani kemoterapi. Pada kelompok umur 3039 tahun mengalami penurunan kepatuhan membawa anaknya menjalani kemoterapi, diikuti kelompok umur 4049 tahun, $3(43 \%)$ dari 7 orangtua tidak patuh.

\section{SARAN}

Kepada para profesional kesehatan untuk memberikan support sistem kepada orangtua yang mempunyai anak dengan leukemia agar patuh dalam menjalani terapi kemoterapi yang telah ditetapkan oleh profesional kesehatan. Para profesional kesehatan harus menjelaskan tentang prosedur kemoterapi, dampaknya dan hal-hal yang perlu dilakukan agar orangtua tetap bersemangat membawa anaknya mengikuti prosedur kemoterapi secara teratur sesuai regimen pengobatan

\section{DAFTAR PUSTAKA}

American Cancer Society. (2009). Children and cancer: Information and resources. diperoleh tanggal 19 Februari 2011.

Ashley, S.M. (2008). Rare hematological malignancies. New York: Springer-Heidelberg.

Campbell, L.K., Scaduto, M., Slyke, D.V., Niarhos, F., Whitlock, J.A., \& Compas, B.E. (2008b). Executive function, coping, and behavior in survivors of childhood acute lymphocytic leukemia. Journal of Pediatric Psychology, 34(3) 317-327.

Cecily \& Linda. 2009. Buku Saku Keperawatan Pediatri edisi 5. EGC, Jakarta

Duchoslav, R.L. (2010). The effects of pediatric acute lymphoblastic leukemia on social competence: an investigation into the first three months of treatment; A thesis of Psychology. Utah State University, Logan, Utah digitalcommons.usu.edu/cgi/ viewcontent.cgi? article $=1545$.

Hurlock, E.B. (1980). Development psychology: A lifespan approach, ed-5. (terj. Psikologi perkembangan; suatu pendekatan sepanjang rentang kehidupan. oleh: Istiwidayanti \& Soedjarwo). Jakarta: Erlangga.

Luxner, K.L. (2005). Delmar's pediatric nursing care plans, $3^{\text {rd }}$ Ed. Clifton Park: Thomson Learning. $\mathrm{P}$ 619-632.

Meyer, E.C., Ritholz, M.D., Burns, J.P., \& Truog, R.D. (2006). Improving the quality of end-of-life care in the pediatric intensive care unit : parents' priorities and recommendations. Journal Pediatrics; 117,649657.

Niven, Niel. 2009. Psikologi Kesehatan, EGC.Jakarta

Notoatmodjo, Soekidjo. 2003. Ilmu Kesehatan Masyarakat, Rineka Cipta. Jakarta

Permono, B., Sutaryo., Ugrasena, I,D,G., Windiastuti, E., \& Abdulsalam, M. (2010). Hematologi-onkologi anak, buku ajar. Ikatan Dokter Anak Indonesia.

Savage, E., Riordan,A.O., \& Hughes, M. (2008). Quality of life in children with acute lymphoblastic leukaemia: a systematic review. European Journal of Oncology Nursing. 30, 1-13.

Smert \& Bart. 1994. Psikologi Kesehatan, Grasindo. Jakatra.

Sondheimer, J.M. (2008). Current essential pediatric. Colorado: The McGraw-Hill Companies, Inc.

Supandiman, Iman.2006. Hematologi Klinik, P.T.Alumni. Bandung. 